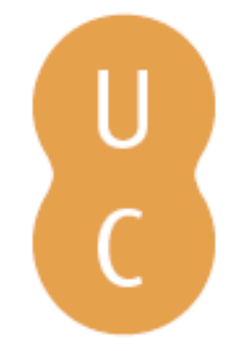

\title{
pommalina
}

\section{Fatores condicionantes da exploração de granito ornamental: o exemplo dos granitos meteorizados da região de Vila Real}
Autor(es):
Sousa, L. M. O.; Oliveira, A. S.; Lourenço, J. M. M.; Capela, I. M. C.
Publicado por: Imprensa da Universidade de Coimbra
URL
persistente:
URI:http://hdl.handle.net/10316.2/31499
DOI:
DOI:http://dx.doi.org/10.14195/978-989-26-0531-9_51
Accessed : $\quad$ 26-Apr-2023 11:18:18

A navegação consulta e descarregamento dos títulos inseridos nas Bibliotecas Digitais UC Digitalis, UC Pombalina e UC Impactum, pressupõem a aceitação plena e sem reservas dos Termos e Condições de Uso destas Bibliotecas Digitais, disponíveis em https://digitalis.uc.pt/pt-pt/termos.

Conforme exposto nos referidos Termos e Condições de Uso, o descarregamento de títulos de acesso restrito requer uma licença válida de autorização devendo o utilizador aceder ao(s) documento(s) a partir de um endereço de IP da instituição detentora da supramencionada licença.

Ao utilizador é apenas permitido o descarregamento para uso pessoal, pelo que o emprego do(s) título(s) descarregado(s) para outro fim, designadamente comercial, carece de autorização do respetivo autor ou editor da obra.

Na medida em que todas as obras da UC Digitalis se encontram protegidas pelo Código do Direito de Autor e Direitos Conexos e demais legislação aplicável, toda a cópia, parcial ou total, deste documento, nos casos em que é legalmente admitida, deverá conter ou fazer-se acompanhar por este aviso.

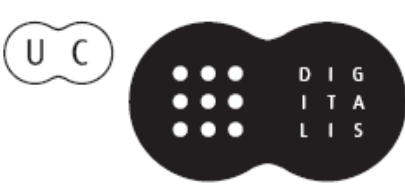





\title{
FATORES CONDICIONANTES DA EXPLORAÇÁO DE GRANITO ORNAMENTAL. O EXEMPLO DOS GRANITOS METEORIZADOS DA REGIÁO DE VILA REAL
}

\author{
CONDITIONING FACTORS IN ORNAMENTAL GRANITE \\ EXPLOITATION. THE EXAMPLE OF THE WHEATERED \\ GRANITES FROM VILA REAL REGION
}

L. M. O. Sousa ${ }^{1}$, A. S. Oliveira ${ }^{2}$ J. M. M. Lourenço ${ }^{1} \&$ I. M. C. Capela ${ }^{3}$

\begin{abstract}
Resumo - A exploração de rochas ornamentais é condicionada por muitos e variados fatores, uns relacionados com as características do material e outros relacionados com as condicionantes impostas pelas normas de ordenamento do território. Neste trabalho enumeram-se as principais condicionantes que limitam a exploração de dois granitos muito importantes da região de Vila Real (norte de Portugal), o granito Amarelo Real e o granito de Mondim de Basto. Trata-se de dois granitos muito meteorizados, incluídos nos designados granitos amarelos, cuja exploração apresenta muitas limitaçôes, sobretudo relacionadas com o grau de fracturação e com o ordenamento do território. O granito de Mondim de Basto apresenta-se mais fraturado e as pedreiras têm menor rendimento.
\end{abstract}

Palavras-chave - granito amarelo, exploração, fatores condicionantes, Vila Real

Abstract - The exploitation of ornamental rocks is conditioned by several and different factors. Some of these factors are related with the material characteristics and others with the limitations arising from land-use planning rules. In this work are listed the main limitations to the exploration of two important granites from the Vila Real region (north of Portugal):

\footnotetext{
${ }^{1}$ Departamento de Geologia, Universidade de Trás-os-Montes e Alto Douro, Apartado 1013, 5001-801 Vila Real; Centro de Geociências da Universidade de Coimbra, Lgo Marquês de Pombal 3000-272 Coimbra, Portugal; 1sousa@utad.pt; martinho@utad.pt

${ }^{2}$ Departamento de Geologia, Universidade de Trás-os-Montes e Alto Douro, Apartado 1013, 5001-801 Vila Real; de Geofísica da Universidade de Coimbra, Av. Dr. Dias da Silva, 3000-134 Coimbra, Portugal; soliveir@utad.pt

${ }_{3}^{3}$ Departamento de Geologia, Universidade de Trás-os-Montes e Alto Douro, Apartado 1013, 5001-801 Vila Real; irenecapela@gmail.com
} 
Amarelo Real and Mondim de Basto granites. They are weathered granites, from the yellow group, whose exploitation is limited by the fracturing and land-use planning. The fracturing is higher in the Mondim de Basto granite and the quarries have lower yield.

Keywords - yellow granite, exploitation, conditioning factors, Vila Real

\section{1 - Introdução}

As rochas utilizadas para fim ornamental devem possuir elevados padrôes de qualidade de modo a que o seu comportamento em obra seja o expectável em todas as situaçôes ambientais. Numa campanha de prospeção para a seleção dos melhores locais para a extração devem ser considerados vários fatores, tais como a composição mineralógica, textura, estrutura, grau de fraturaçáo, espessura do material de cobertura sem interesse comercial, propriedades físico-mecânicas, impacte ambiental e ordenamento do território (CARVALHO et al., 2008; FORT et al., 2010; SOUSA, 2010). Estes fatores podem ser agrupados em três grandes grupos, um relativo à rocha, outro ao afloramento e um outro relacionado com os fatores de explorabilidade (Tabela 1). Os dois primeiros grupos englobam fatores intrínsecos ao material e não são suscetíveis de alteração ao longo do tempo, enquanto os fatores de explorabilidade podem ser modificados, facilitando ou dificultando a atividade extrativa. Em última análise são os fatores de explorabilidade que ditam a possibilidade de instalar uma unidade extrativa, pois de nada valerá ter uma rocha com boas características estéticas se a sua exploração for interdita, por exemplo, por questôes de ordenamento de território.

Tabela 1 - Exemplos de fatores que condicionam a exploração de rochas ornamentais.

\begin{tabular}{|c|c|c|}
\hline Material & Afloramento & Explorabilidade \\
\hline Mineralogia & Localização & Aceitação pelo mercado \\
\hline Textura & Morfologia & $\begin{array}{l}\text { Distância aos centros de } \\
\text { consumo }\end{array}$ \\
\hline Heterogeneidade (cor, textura) & Terrenos de cobertura & Infra-estruturas industriais \\
\hline Meteorização & Estrutura (estratos, dobras) & Ordenamento do território \\
\hline Propriedades físicas & Variação de fácies & Impactes ambientais \\
\hline \multirow[t]{2}{*}{ Propriedades mecânicas } & Fraturação (tipo, densidade) & \\
\hline & Volume disponível & \\
\hline
\end{tabular}

A procura de uma rocha, variável ao longo do tempo, é determinada pela valorização dada às suas características texturais e à sua cor. Nas últimas duas décadas tem aumentado a procura de granitos com cores "quentes", como aqueles muito meteorizados, designados de amarelos, em detrimento dos granitos esbranquiçados, cinzentos e cinzentos azulados. Como consequência verificou-se um grande crescimento do número de unidades extrativas naquela tipologia de granitos. As condiçóes geológicas e de exploraçáo inerentes aos granitos meteorizados, especialmente a espessura de meteorização, elevada fraturação e baixa taxa de recuperação, obrigam a que as pedreiras ocupem grandes áreas. Estes dois factos, aumento do número de pedreiras e ocupação de grandes áreas do território, têm originado muitas situaçôes de conflito com as demais valências do território. 
Neste trabalho apresentam-se os casos de dois granitos amarelos da região de Vila Real (norte de Portugal), o granito Amarelo Real (designação comercial) e o granito de Mondim de Basto, que constituem importantes polos de desenvolvimento regional devido à importância das atividades económicas a eles ligadas. Para cada um dos granitos referem-se os principais fatores condicionantes do seu aproveitamento como rocha ornamental e as açóes que visam o ordenamento das zonas de exploração.

\section{2 - Granitos estudados}

Os granitos abordados neste trabalho, Amarelo Real e Mondim de Basto, localizam-se no norte de Portugal e constituem maciços relativamente circunscritos (Fig. 1). As exploraçóes do granito de Mondim de Basto localizam-se cerca de $2 \mathrm{~km}$ a nordeste de Mondim de Basto, no sopé do Monte Farinha. As exploraçóes do granito Amarelo Real localizam-se na serra da Falperra, cerca de $10 \mathrm{~km}$ a nordeste de Vila Real.

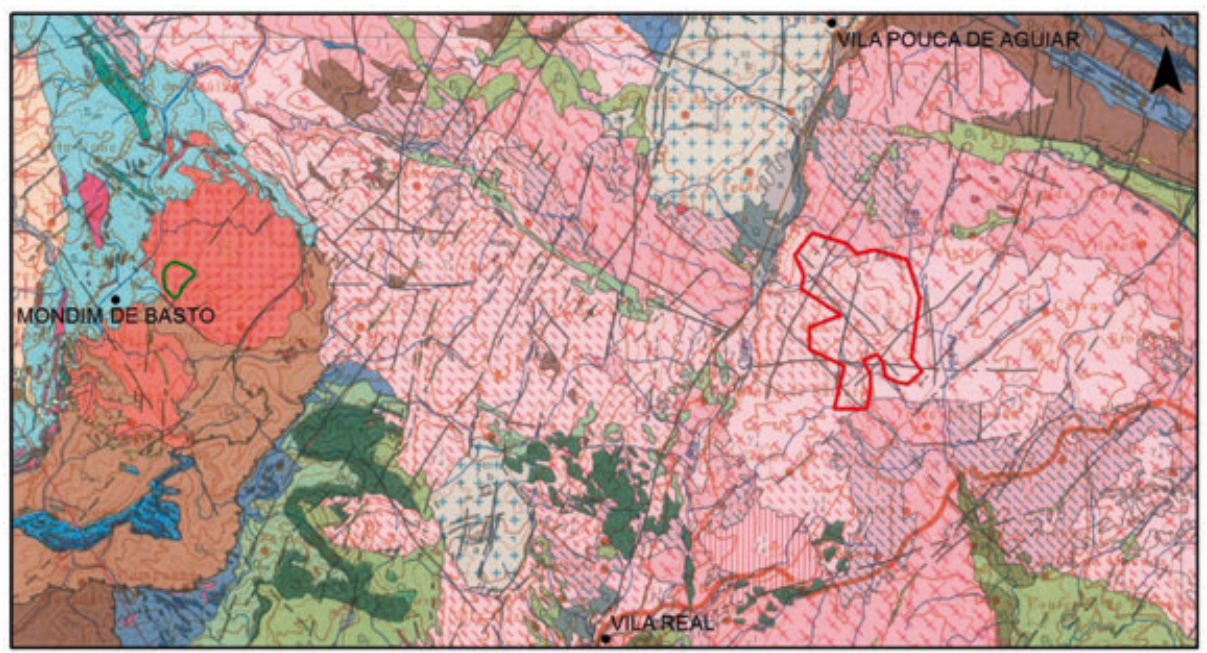

\section{Legenda}

Área de reserva na Serra da Falperra

Núcleo de pedreiras de Mondim de Basto

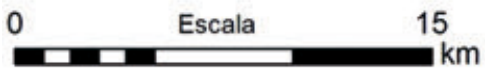

Granito de grão médio a grosseiro, porfirbide, de duas micas (S.

Granito de grão médio a grosseiro,com esparsos megacristais, de duas micas

Granito de grằ grosseiro a médio, porfiróide, de duas micas

Granito de grăo médio a grosseiro:

Granito de grăa médio a grosseiro:

granito de grăo médio com esparsos megacristais ( ${ }^{(*)}$ (Sra da Graça)

Excerto da folha $n^{\circ} 2$ da Carta Geológica de Portugal à escala 1:200.000

Fig.1 - Localização dos granitos estudados.

O granito de Mondim de Basto é um granito de duas micas, de granularidade média, por vezes com megacristais de feldspato, com foliaçáo aproximada NW-SE. Como minerais principais, apresenta quartzo, microclina-pertite, microclina sódica, moscovite e biotite, (PEREIRA, 1987). As pedreiras, de pequena dimensão, têm como condição 
necessária à sua viabilidade o aproveitamento dos fragmentos de pequena dimensão para obtenção de peças fendidas e serradas, pois são raras as grandes massas que possibilitem a extração de blocos de primeira qualidade para transformação em engenho. O número de pedreiras ativas ascende a vinte e duas, mas apenas três possuem a respetiva licença de exploração.

O granito Amarelo Real possui grão médio ou médio a grosseiro, é de duas micas, com predominância da moscovite, e tem leve tendência porfiroide. A composição mineralógica modal é a seguinte: quartzo (35,8\%), feldspato potássico (23,6\%), plagioclase $(29,3 \%)$, biotite $(3,3 \%)$, moscovite $(7,9 \%)$ e apatite $(0,1 \%)$, que o classifica como monzogranito (SOUSA, 2007). As pedreiras têm, de um modo geral dimensão elevada, próximo de 5 ha, e nelas é possível obter blocos de grande volume para a indústria transformadora, sendo este o principal produto obtido. Atualmente as pedreiras ativas são cerca de quinze, todas elas licenciadas, embora a diminuição da procura tenha causado o encerramento temporário de muitas unidades e a diminuição do volume extraído.

\section{3 - Fatores condicionantes}

Nesta secção apresentam-se apenas os fatores identificados como os mais limitativos para a exploração dos granitos amarelos: as heterogeneidades cromáticas, a fraturação e o ordenamento do território.

\section{1 - Heterogeneidades}

O valor comercial destes granitos, e de todos aqueles com coloração similar, advém da sua tonalidade e, como tal, a existência de grandes massas com coloração homogénea é uma condição necessária ao sucesso das pedreiras. Em ambos os granitos são frequentes heterogeneidades cromáticas associadas a zonas de fratura que condicionaram a intensidade de meteorização (Fig. 2). A variação brusca do estado de meteorização, e consequentemente da cor da rocha, limita a obtenção de blocos com coloração homogénea e diminui o respetivo valor comercial, pois estes blocos não serão utilizados para produção de chapa polida. Como a meteorização é mais intensa nos níveis superiores do maciço, a extração em profundidade é inviabilizada pelo aspeto cada vez mais são do granito, embora esta profundidade varie de local para local em função do padrão da fraturação. Uma consequência imediata deste facto é a necessidade de realizar a extração destes granitos em grandes áreas e, de um modo geral, todas as grandes pedreiras apresentam uma extensão areal assinalável, frequentemente superior a 5 ha. 


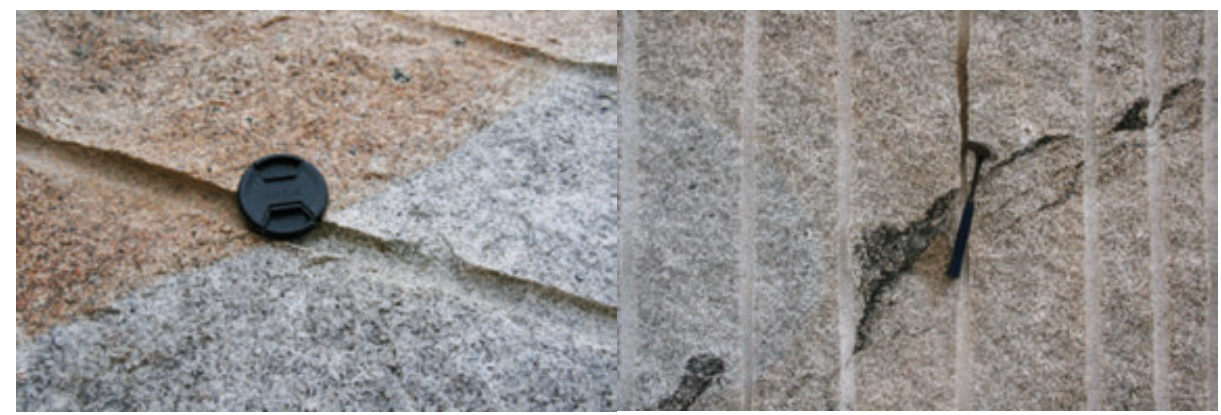

Fig. 2 - Algumas heterogeneidades que são comuns aos dois granitos estudados

(esquerda: variação cromática;

direita: schlieren biotítico).

Outras heterogeneidades relacionadas com a presença de nódulos e veios biotíticos (Fig 2), variaçôes granulométricas e filóes de constituição variada não são muito penalizantes, dada a sua baixa frequência e localização pontual, quando comparadas com a variação de cor.

\section{2 - Fraturaçáo}

A fraturaçáo dos maciços revela-se como sendo o fator mais limitante para uma exploração economicamente rentável deste granitos, pois determina o tamanho e forma dos blocos que podem ser extraídos.

No granito Amarelo Real os lineamentos observados em fotografia aérea têm a direção preferencial $\mathrm{N} 30^{\circ}-60^{\circ} \mathrm{W}$, ocorrendo ainda lineamentos de menor expressão com as direçóes $\mathrm{N} 20^{\circ}-40^{\circ} \mathrm{E}$ e $\mathrm{N} 70^{\circ}-90^{\circ} \mathrm{E}$. No granito de Mondim de Basto é possível identificar as famílias $\mathrm{N}-\mathrm{S}$, com maior representatividade no sector este da área, as famílias $\mathrm{N} 20^{\circ}-30^{\circ} \mathrm{E}$ e $\mathrm{N} 50^{\circ}-60^{\circ} \mathrm{E}$, que consistem num conjunto de fraturas extensas, e a família $\mathrm{N} 70^{\circ}-80^{\circ} \mathrm{W}$, mais frequente a noroeste do Monte Farinha (Fig. 3).

Os estudos da fraturação realizados nos vários locais explorados permitiram determinar as principais famílias de diaclases, a respetiva orientação e espaçamento médio. De um modo geral há uma estreita relação entre a fraturação regional e o diaclasamento local, com variaçôes pontuais em alguns locais. No granito Amarelo Real verifica-se o predomínio de duas famílias de diaclases, uma mais marcada $\left(\mathrm{N} 30^{\circ}-50^{\circ} \mathrm{W}\right)$ e outra mais ampla mas de maior importância relativa (N20\%-60E) (Fig. 4). No granito de Mondim de Basto também se verifica a presença de duas famílias predominantes (N-S e E-W), mas em todas as direçóes há um número significativo de diaclases (Fig. 4). Da análise comparativa poderemos afirmar que no conjunto das exploraçôes do granito de Mondim de Basto as diaclases apresentam uma maior variabilidade direcional, facto que penaliza a obtenção de blocos com forma cúbica ou paralelepipédica. Nas pedreiras do granito Amarelo Real é mais comum a existência de uma ou duas famílias de diaclases. 


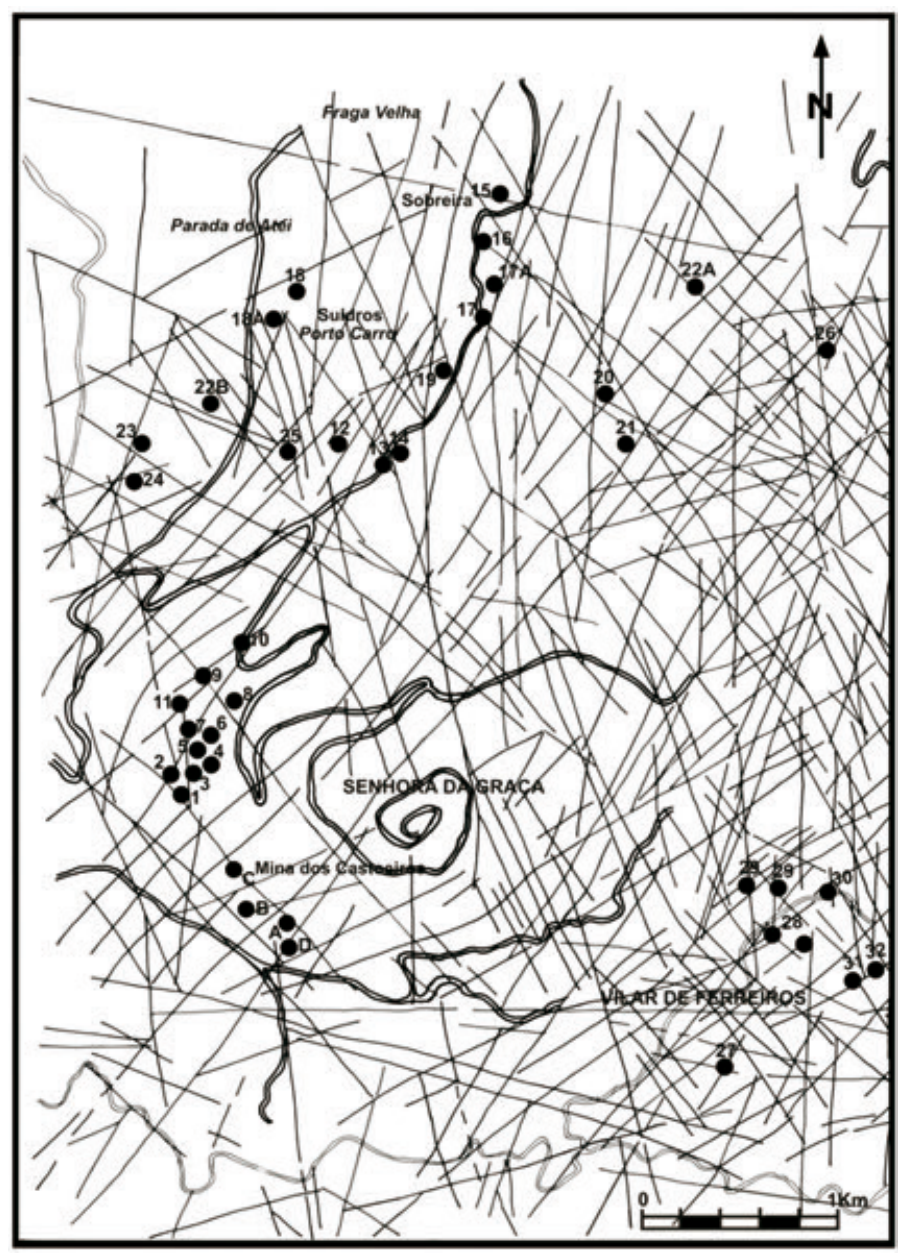

Fig. 3 - Lineamentos observados na fotografia aérea da regiāo do Monte Farinha (os pontos assinalados dizem respeito aos locais onde se procedeu a estudos de diaclasamento) (adaptado de ALVES, 2010).

O espaçamento médio, associado ao número de famílias de diaclases, pode dar uma indicação do grau de fraturação do maciço. Os valores obtidos para este parâmetro são influenciados pela tipologia de locais escolhidos para a obtenção de dados: locais de extração, selecionados aleatoriamente ou selecionados de acordo com algumas condicionantes. Para o granito Amarelo Real foram obtidos, em três estudos diferentes, valores do espaçamento médio de $1,0 \mathrm{~m}, 1,3 \mathrm{~m}$ e 1,5 m (SOUSA, 2007). Nos locais de exploração do granito de Mondim de Basto foi obtido um valor de $0,8 \mathrm{~m}$, ligeiramente inferior ao valor obtido em circunstâncias idênticas no granito Amarelo Real (1,0 m). Estes valores são muito baixos e indicam-nos que a quantidade de material sem aproveitamento comercial é elevada. A gestáo desta quantidade de escombros, que acarreta uma elevada despesa, é inerente às exploraçôes deste tipo de granitos. Este facto, aliado à evolução em extensão das pedreiras, é causa de importantes impactes visuais em muitas das situaçôes. 


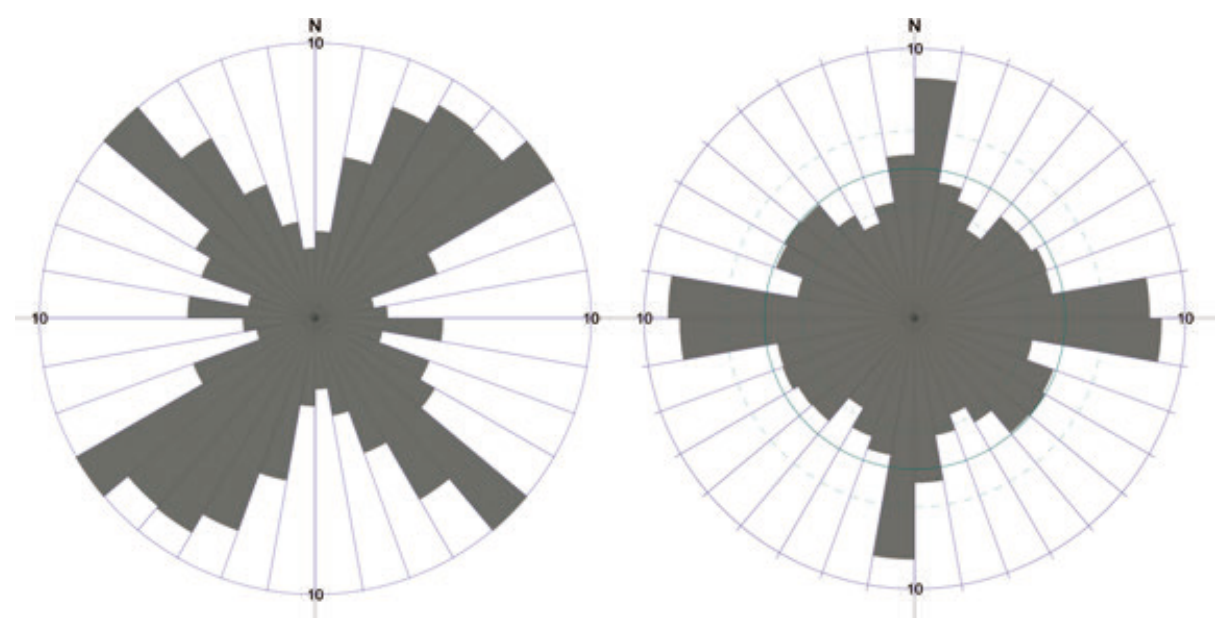

Fig. 4 - Diagramas de rosetas do diaclasamento nos locais de exploraçấo (esquerda: granito Amarelo Real; direita: granito de Mondim de Basto).

Da análise conjunta dos dados relativos à fraturação, é nítida a situação mais desfavorável no granito de Mondim de Basto. Nas exploraçóes deste granito verifica-se uma maior variabilidade da direção do diaclasamento, ou seja maior número de famílias de diaclases, e também um menor espaçamento médio dessas mesmas diaclases. Estes factos justificam o baixo rendimento das pedreiras do granito de Mondim de Basto e a necessidade de se proceder ao aproveitamento dos blocos irregulares para produtos de cantaria.

\section{3 - Ordenamento do território}

A localização geográfica dos recursos geológicos resulta estritamente dos acontecimentos geológicos e não poder ser modificada. Destes factos poderáo surgir conflitos de interesses quando as diferentes valências de um mesmo território forem incompatíveis. Os planos de ordenamento do território, salvo raras exceçôes, não consideram a informação relativa aos recursos geológicos, originando conflitos pela dificuldade em licenciar a sua exploração. A situação destes dois granitos é muito diferente no que respeita às consequências do ordenamento do território.

A área de exploração do granito Amarelo Real está enquadrada numa zona de reserva (Fig. 5), a Área de Reserva na serra da Falperra (Decreto Regulamentar no6/2009, de 2 de abril). Esta área de reserva é o reconhecimento da importância económica e social das atividades extrativa e transformadora associadas a este granito, e a sua definição teve consequências benéficas para o ordenamento da exploração. Todas as pedreiras em atividade possuem licença de exploração e há uma maior e melhor fiscalização.

A área de extração do granito de Mondim de Basto, devido à sua localização numa zona emblemática, o Monte Farinha, e a diversos constrangimentos de ordenamento do território, nomeadamente a Reserva Ecológica e a Rede Natura 2000, apresenta uma difícil sustentabilidade a longo prazo. O processo de licenciamento das pedreiras foi 
iniciado há já alguns anos e até à data apenas em três casos foi concluído com êxito. Os promotores foram obrigados a licenciar as áreas possíveis, aquelas onde o Plano Diretor Municipal permitia a instalação de pedreiras, e não aquelas que seriam necessárias ao desenvolvimento normal da atividade extrativa (Fig. 6).

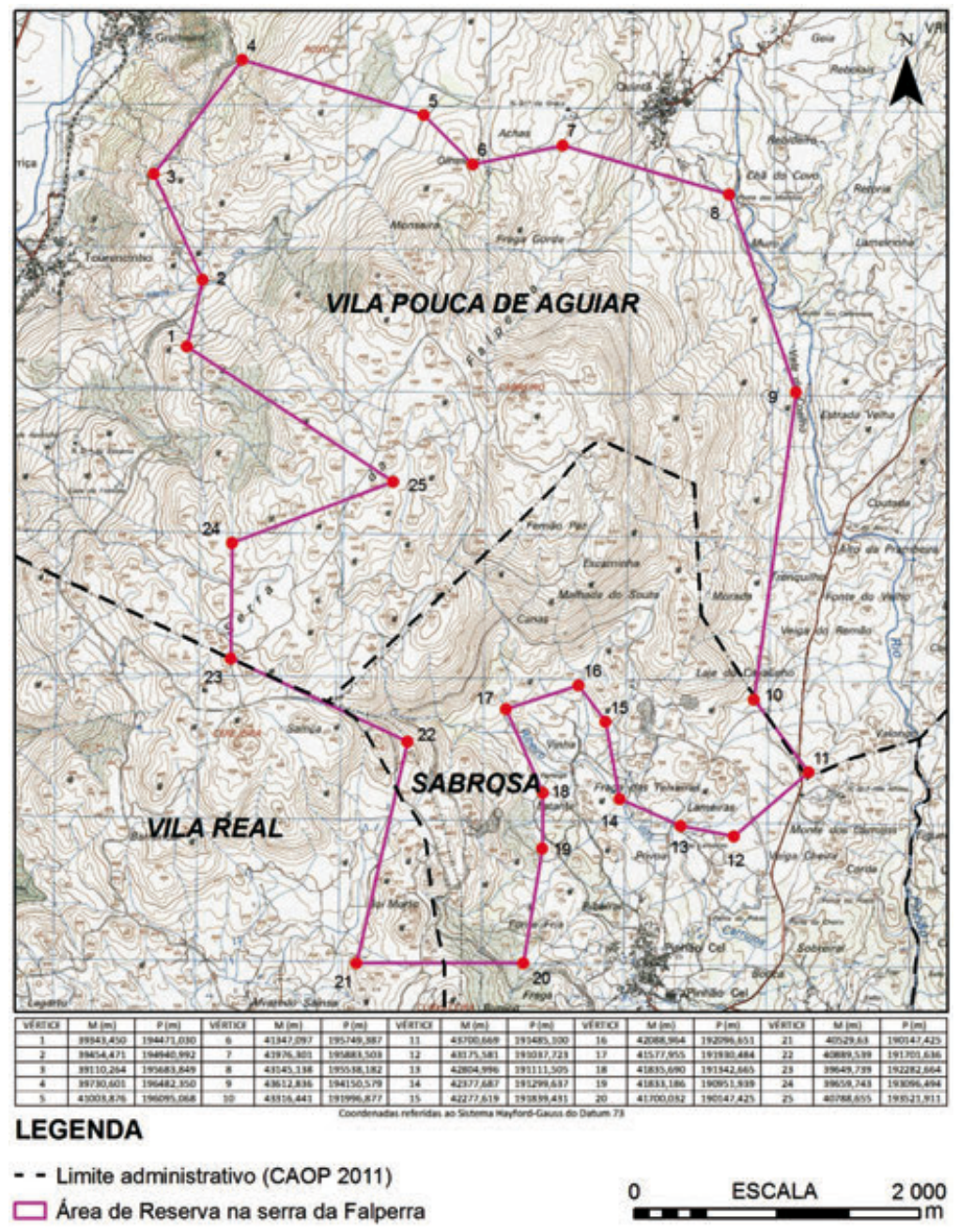

Fig. 5 - Poligonal da Area de Reserva na serra da Falperra (excerto das folhas nos 88 e 102 da Carta Militar de Portugal, Série M888; Limites administrativos publicados na Carta Administrativa Oficial de Portugal (IGP, 2011)).

Como atrás foi referido, a extração deste tipo de granitos, necessita de grandes áreas para obstar à pouca profundidade útil do depósito e à elevada percentagem de escombros resultantes. Assim, caso não haja modificação da atual situação será difícil licenciar pedreiras com dimensão suficiente que assegure a sua viabilidade futura, contribuindo-se assim para a manutenção de situaçóes dúbias sob o posto de vista legal. 


\section{4 - Considerações finais}

Os granitos estudados apresentam características típicas dos designados granitos amarelos, nomeadamente elevada meteorização que lhe confere uma coloraçáo muito variável em função da ação local dos agentes meteóricos. A densidade de fraturação é muito elevada em ambos os granitos, mas o espaçamento médio é maior no granito Amarelo Real $(1,0 \mathrm{~m})$ do que no granito de Mondim de Basto $(0,8 \mathrm{~m})$. A diminuição da intensidade de meteorização em profundidade e a baixa taxa de recuperação levam à necessidade de ocupação de grandes áreas de extração de modo a permitir uma exploração economicamente rentável. As condicionantes ditadas pelo ordenamento do território estão a limitar a exploração deste recurso na região de Mondim de Basto, com prejuízos pela não extração e pelos impactes ambientais resultantes que não são cabalmente controlados.

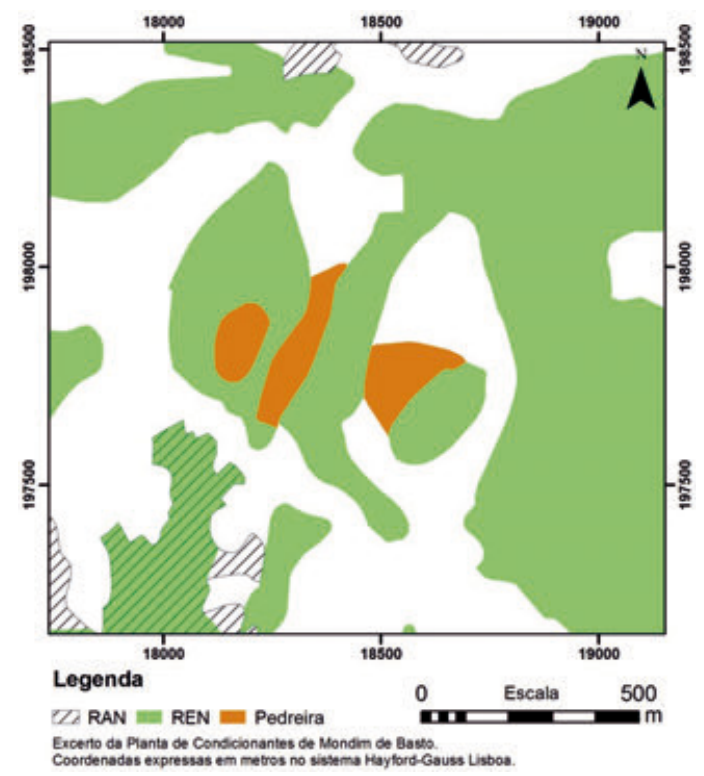

Fig. 6 - As áreas propostas para licenciamento de pedreiras são limitadas pelas condicionantes do PDM local, neste caso pelas áreas de Reserva Ecológica.

Agradecimentos - Este trabalho foi realizado com o apoio financeiro do Centro de Geociências e do Centro de Geofísica, da Universidade de Coimbra.

\section{Referências Bibliográficas}

ALVES. I. M. C. (2010) - Exploração de granito em Mondim de Basto: caracterização e potencialidades didácticas. Tese de Mestrado. Universidade de Trás-os-Montes e Alto Douro.

CARVALHO, J. F., HENRIQUES, P., FALÉ, P. \& LUÍS, G. (2008) - Decision criteria for the exploration of ornamental-stone deposits: Application to the marbles of the Portuguese Estremoz Anticline. International Journal of Rock Mechanics and Mining Sciences, 45(8), p.1306-1319. 
DECRETO REGULAMENTAR n6/2009. Diário da República, 1.a série, N.o 65, 2 de Abril de 2009, pp. 2050-2052.

FORT, R., BUERGO, M. A., PEREZ-MONSERRAT, E. \& VARAS, M. J. (2010) - Characterisation of monzogranitic batholiths as a supply source for heritage construction in the northwest of Madrid. Engineering Geology, 115(3-4), p. 149-157.

INSTITUTO GEOGRÁFICO PORTUGÛES (2011) - Carta Administrativa Oficial de Portugal. http://www. igeo.pt/produtos/cadastro/caop/inicial.htm (consultado em 2012.01.15)

PEREIRA, E. (1987) - Estudo geológico-estrutural da região de Celorico de Basto e a sua interpretação geodinâmica. Dissertação de Doutoramento. Faculdade de Ciências, Universidade de Lisboa.

SOUSA, L.M.O. (2007) - Granito Amarelo Real: características gerais e contribuição para o ordenamento da exploração na serra da Falperra. Boletim de Minas, 41(2), p. 161-174.

SOUSA, L.M.O. (2010) - Evaluation of joints in granitic outcrops for dimension stone exploitation. Quarterly Journal of Engineering Geology and Hydrogeology, 43, p. 85-94. 